\title{
ANTIGÜEDAD TARDÍA, NEOPLATONISMO Y CRISTIANISMO: SOLUCIONES DE AYER PARA PROBLEMAS DE HOY José Molina Ayala*
}

RESUMEN: Se presenta un panorama general de la Antigüedad tardía, más específicamente sobre el siglo tercero, y se expone cómo en ese período tanto el cristianismo como el neoplatonismo, y de manera prominente el filósofo Jámblico, elaboraron una síntesis entre religión, filosofía y paxis ética.

PALABRAS CLAVE: Antigüedad tardía, neoplatonismo, cristianismo, Jámblico, Protréptico.

RECEPCIÓN: 3 de diciembre de 2008.

ACEPTACIÓN: 11 de febrero de 2009.
ABSTRACT: This article presents a general overview of Late Antiquity, more specifically, the third Century, emphasizing how during these times Christianity, Neo-Platonism, and most notably, the philosopher Iamblichus, created a synthesis between religion, philosophy, and the practice of ethical principles.

KEYWORDS: Late Antiquity, Neoplatonism, Christianity, Iamblichus, Protrepticus.

* Centro de Estudios Clásicos, Instituto de Investigaciones Filológicas, Universidad Nacional Autónoma de México. 


\author{
ANTIGÜEDAD TARDÍA, \\ NEOPLATONISMO \\ Y CRISTIANISMO: \\ SOLUCIONES DE AYER \\ PARA PROBLEMAS DE HOY
}

La psicología nos ha enseñado que si nos asomamos a nuestro pasado, no sólo con valentía, sino también con prudencia, podemos valorar justamente las páginas oscuras de nuestra historia personal; y transformar lo que acaso sin saberlo es obstáculo de nuestro crecimiento en apoyo de nuestra realización. Eso mismo que ocurre en el plano personal, sucede si revisamos nuestra historia patria, y seremos distintos unos de otros de acuerdo con la idea que cada uno tenga del significado de la Conquista y de los años de Colonia, y de todos esos traumas históricos que ha vivido nuestra patria. Hoy quisiera, sin embargo, ir más arriba y mirar la historia de la humanidad en un período que, como veremos, es de gran importancia para nosotros. Ese período lo han denominado los historiadores "la Antigüedad tardía". Se trata, poco más o menos, del período que abarca desde la muerte de Marco Aurelio, el emperador filósofo, hasta la caída del imperio romano, cuando las paradojas de la historia quisieron que el último emperador de Roma se llamara Rómulo, justamente como el fundador de la antigua urbe; es decir, desde el año 180 hasta el 470 después de Cristo, aproximadamente.

La Antigüedad tardía había sido un período descuidado por los historiadores, pensadores y filósofos por muchas razones, $y$, sin embargo, en ella, y no en la Antigüedad clásica, están los gérmenes de lo que llegaría a ser la Europa cristiana, que a la postre, bajo la égida española, llegará a 
conquistar nuestras tierras. Las razones que habían hecho precisamente que se considerara éste un período sin interés o sin relación alguna con nuestra vida moderna, siguen afectándonos.

Las razones por las que este período ha sido visto con recelo se originaron desde hace mucho tiempo. Ya Quevedo en célebre soneto hacía notar que de la gloria de Roma sólo quedaba el Tibre, como él lo llama, “joh Roma! -decía el poeta- En tu grandeza, en tu hermosura, / huyó lo que era firme, y solamente/ lo fugitivo permanece y dura". Más de notar ha sido la poderosa opinión de Edward Gibbon, que escribiera a finales del siglo XVIII su amplísima y maravillosa obra Ruina y decadencia del imperio romano; por su solo nombre, éste, en la mente del historiador inglés, no es sólo un período de estancamiento, sino también de retroceso; en su visión racionalista la historia de esta época no es sino una elegía; él mismo decía como un lamento "he descrito el triunfo de la barbarie y la religión". A tal punto llegó su influencia que ya entre nosotros Sofía Loren no perdió la oportunidad de llevar la obra del historiador a las salas de cine, y de difundir así esa visión de catástrofe. De manera que, quienes miraron la gloria y majestad de los períodos así considerados y llamados clásicos, de griegos y romanos, no iban a dedicar afanes a la ruina y la decadencia de lo que se pensaban ser los máximos logros del espíritu humano.

Otro prejuicio en contra del estudio de la Antigüedad tardía nació con el Iluminismo francés, y de manera concreta con uno de sus más prominentes retoños que fue el positivismo. Cabe recordar, para hacer una relación aunque sea pequeña pero muy cercana a nosotros, que Justo Sierra, fundador de la Universidad Nacional, fue alumno directo de Augusto Comte, iniciador de aquella corriente del pensamiento. Simplificando en extremo, para mi propósito basta decir que el iluminismo exaltaba la luz de la razón; pero no cualquiera, sino la de la idea clara y distinta; la que huía a ultranza del oscurantismo -así considerado por ellos y no por pocos de nosotrosde la Edad Media; se paseaba la diosa razón por las calles de París, la ciudad luz; Nôtre Dame no es más la Madre del Salvador, sino la luz del entendimiento que disipa las tinieblas de la religión. Comte, por su parte, convoca a todos a conseguir la libertad mediante el dato positivo: la ciencia está llamada a dejar atrás la explicación religiosa y estética del mundo. La divisa en boga, todavía en la bandera del Brasil, es "orden y progreso". Con esta mentalidad, por no hablar de la más contemporánea posmodernidad, tenía pocas 
NOTAS

probabilidades de ser valorado justamente el período de la historia donde lo religioso, lo que está más allá de este mundo, es lo más real. En efecto, la religiosidad y la metafísica son características de la Antigüedad tardía; en ella, por un proceso al que me referiré más adelante, el cristianismo se vuelve la religión oficial del imperio. Poco a poco, los pueblos europeos entran en la Iglesia, y, posteriormente, justo a raíz del iluminismo los Estados comienzan a salir de ella, haciéndose laicos y reclamando su independencia de la Iglesia. Esto, en nuestro país y en otra proporción, también ha sido vivido tras las Leyes de Reforma, cuya laicidad de la educación significó en muchos casos, de hecho ateísmo, jacobinismo, anticlericalismo.

Habida cuenta de todas estas dificultades para despertar nuestro interés por la Antigüedad tardía, bastará fijar nuestra atención no en todo este largo período sino tan sólo en el siglo tercero después de Cristo.

Recientemente, el desarrollo de los medios de comunicación ha obligado a reflexionar sobre la llamada "sociedad global". Todos en todas partes llegarán a vestir la misma ropa, a ver los mismos libros, a estar preocupados por los mismos problemas, etcétera. En el siglo III, el territorio conquistado por los romanos vivía también, con las debidas proporciones, una "monocultura", que conocemos con el nombre de helenismo, el cual se había extendido en todo el Mediterráneo desde el siglo segundo antes de Cristo. Los caminos del imperio romano permitieron a Septimio Severo avanzar rápidamente y ganar la guerra civil; para entonces, se podría decir que todo el territorio romano estaba comunicado. Así como ahora, poco a poco, las ciudades se van llenando de edificios de acero y de cristal, entonces los acueductos, los arcos de medio punto y la columna corintia se hallaban a lo largo de todo el imperio. Más aún, el griego y el latín se hablaban indistintamente, aunque hay que decir que el carácter bilingüe de la cultura se perdió precisamente en el siglo III, debido a los conflictos sociales. Hacia el año 212, el emperador Caracalla concede con la Constitutio Antoniniana, la ciudadanía a todos los habitantes libres, lo que consecuentemente trajo una unificación quizá más eficaz que la que pretende la actual Comunidad Económica Europea. Así, el imperialismo romano deja su impronta en la cultura, en la religión y en la filosofía.

Sin embargo, el imperialismo encontró su contraparte en el individuo; éste emergió con sus potencialidades de una manera más clara y con mayor vigor, porque tenía la necesidad de encontrar respuestas a pregun- 
tas que no se habían formulado en el pequeño ámbito de su ciudad, aunque el concepto general y abstracto de "humanidad" favorecía el aparato imperial, pues una sociedad individualista no puede oponerse a un gobierno que reorganiza los grupos sociales transformándolos en extensiones de su propia autoridad. La sociedad civil se opuso espontáneamente a la globalización de entonces, agrupándose en toda clase de tendencias que aglutinaban a los individuos con más o menos éxito; las agrupaciones de la sociedad civil, intelectuales, políticas o religiosas, le daban al individuo el respaldo de la pertenencia, que no podía darle ya su ciudad ni la lejana autoridad del emperador; algo semejante, si no idéntico, ocurría en los años sesenta del siglo pasado, cuando era importante por ejemplo pertenecer al partido.

Ahora bien, a mediados del siglo tercero, el imperio romano no era económicamente homogéneo, sino que estaba dividido en Oriente y Occidente, de manera análoga a la actual división entre los países del Norte y los del Sur; en aquel entonces, pertenecer a la región oriental implicaba, sobre todo, vivir en una región próspera, productiva, capaz de hacer frente a la inflación de la época, a los altos impuestos requeridos por un aparato estatal altamente militarizado y burocratizado.
En lo político, el Oriente tuvo una mayor injerencia en los asuntos del gobierno, en parte por su auge económico, pero también por su posición estratégica. Esta tendencia se asumió oficialmente en el régimen de la tetrarquía: el gobierno del imperio se repartía bajo el mando de dos Augustos y dos Césares. Dioclesiano, quien impuso ese régimen, había establecido su residencia en Nicomedia; mientras tanto, Roma había pasado a ser una provincia más dentro del imperio, manteniendo algunos privilegios. Finalmente, Constantino estableció en Bizancio la capital del imperio, reinaugurando en el 330 la ciudad, a la que le dio su nombre.

Por la importancia estratégica de su geografía y por su auge económico, Siria fue, en la segunda mitad del siglo III, el escenario de dos grandes conflictos militares. El primero se debió al propósito declarado del imperio Persa de anexionarse esa región, aprovechando los constantes ataques que los bárbaros dirigían contra el imperio romano en Occidente. Quizá el episodio más significativo fue la derrota y el aprisionamiento del emperador Valeriano, hacia el 260, a manos de Sapor I; no se pagó rescate y el emperador murió en el destierro. El segundo conflicto fue de orden interno. Nunca fue más verdadera que en el siglo III la frase de Tácito: "así la muerte del emperador había promovido varios 
NOTAS

movimientos en los ánimos, no sólo entre la ciudad, entre los padres o entre el pueblo o en el soldado urbano, sino también entre todas las legiones y sus jefes, porque se había divulgado el secreto del imperio de que el príncipe podía ser nombrado en otro lugar fuera de Roma" (Hist., I, 4, 2). Todo el imperio resintió los constantes magnicidios y las luchas civiles consecuentes. Concretamente en Siria, la prosperidad económica y el conflicto con los persas dieron ocasión, por ejemplo, a que la legendaria Zenobia se levantara contra el imperio romano; sin embargo, el emperador Aureliano, hacia el 270, arrasó la ciudad de Palmira, de la cual Zenobia era la reina.

Nuestro siglo XX y este inicio del siglo XXI son un buen ejemplo para comprender mejor la situación general y el estado de ánimo de los habitantes del imperio romano. Como el muro de Berlín en la Europa de la postguerra, el muro que divide la frontera de Estados Unidos con México, o el muro que empieza a levantarse ahora en territorio palestino, la muralla levantada alrededor de Roma por Aureliano fue el signo de las tensiones sociales de la época. Baste mencionar las dos guerras mundiales, la guerra fría, el imperialismo norteamericano, la recesión del 29, la guerra del Golfo y sus secuelas, la invasión a Afganistán tras el 11 de septiembre; más concretamente aquí en México, el conflicto armado en Chiapas, los magnici- dios, la actual crisis económica. No es gratuito y no se crea que exagero el paralelismo entre ésta y aquella época. Por ejemplo, no es gratuito que la revista Nexos de abril de 1995, en alusión a la mencionada obra de Gibbon, llevara como título en la portada "Decadencia y caída del sistema político mexicano. Cinco autopsias". El paralelismo es inevitable. Dodds, utilizando una expresión acuñada por el poeta Auden y referida al siglo XX, denominó a los años que transcurren entre Marco Aurelio y Constantino, "una época de ansiedad". Por cierto, como ahora, tampoco faltaron las calamidades naturales, como la peste que asoló al imperio hacia el 250. En todo caso, lo que quiero señalar es que nuestra situación nos ha hecho más sensibles para acercarnos con nuevos ojos a aquellos tiempos, y nos hemos podido ver a nosotros mismos en ellos.

Hay que decir que gran parte de los conflictos internos del imperio romano, según Rostovtzeff, se debieron, desde el gobierno de los Severos, al problema agrario. La milicia fue uno de los pocos medios, junto con la burocracia, para ascender en el orden social; el ejército estaba formado en su mayoría por la población rural, sobre la que había recaído la fuerte carga de los impuestos y el derroche de los recursos que hacían las ciudades. El nivel de vida en muchos centros urbanos experimentó un enorme atraso y la 
inseguridad se convirtió en una preocupación permanente; las clases nobles, a las cuales favorecieron la situación agraria y los altos impuestos haciéndose terratenientes, se refugiaron en sus villas. Por otra parte, durante el siglo III hubo una gran movilidad social que, aunque no era general ni indiscriminada, permitió a muchos campesinos enriquecerse y a varios soldados ascender en sus cargos políticos; incluso hubo algunos que llegaron a ser la máxima autoridad del imperio.

Los emperadores fracasaron en sus constantes intentos de restaurar el orden, hasta que el caos y la anarquía social encontraron su estabilidad bajo el teocrático gobierno de Diocleciano y de Constantino, cuyas reformas estabilizaron las clases sociales. Rostovtzeff se ocupa en conjunto de las reformas de ambos emperadores, destacando las realizadas al poder imperial, en el sentido de realzar el carácter religioso de la persona del emperador; al ejército, al crear una guardia pretoriana más profesional; a la administración, separándola de la injerencia militar y haciéndola más especializada, por lo cual, se hizo más amplia y centralista; al sistema tributario, buscando sanear los ingresos, estabilizar los precios, cobrando en especie, fijando impuestos según las divisiones de la tierra cultivable, y fijando a los campesinos a la tierra. Estas reformas se trataron de llevar a cabo, acaso sin el éxito esperado, pues quizá no se podían tener en cuenta las distintas situaciones de las provincias, pero sin duda pusieron las bases de la organización feudal del medioevo.

Obviamente estas líneas sólo quieren ser un panorama de la Antigüedad tardía, en general, y del siglo tercero, en particular, que puede llevarnos a comprender mejor aquello en que nuestra situación actual es semejante, y aquello en lo que es diferente. Dispongámonos, pues, a escuchar a los antiguos para saber quiénes somos, y acaso podamos tomar inspiración para dar respuesta a esos problemas que tanto aquejaban a aquellos hombres, como lo pueden seguir haciendo con nosotros.

Vayamos ahora a la situación, digamos "cultural" de entonces, también expuesta en sus líneas más generales.

Como es natural, las actividades intelectuales se desarrollaron en el Oriente, no sin recibir una importante influencia del imperio Sasánida, que por entonces estaba en su apogeo. Las principales personalidades de la cultura de ese tiempo tienen su origen en la parte oriental del Imperio. Ciertamente Orígenes, el famoso teólogo cristiano, y Numenio, el filósofo más influyente del platonismo medio, habían hecho de 
NOTAS

Alejandría en Egipto, y de Apamea, en Asia Menor, respectivamente, los verdaderos centros de la cultura de la época. Hay que tomar en cuenta que Plotino, iniciador del neoplatonismo, era un egipcio que a los veintiocho años inició su formación filosófica bajo la instrucción de Amonio en Alejandría, al lado de Orígenes, y aunque estableció su escuela en Roma, hacia el 244, no lo hizo sino después de haber viajado a la India, acompañando en su expedición al emperador Gordiano III. Porfirio, el discípulo más destacado de Plotino, nació en Tiro o Batanea, en Siria, hacia el 232; es reconocido por su amplia erudición, por el dominio de varios idiomas, entre ellos el hebreo; se distinguió como editor de la obra de su maestro, Las Enéadas, y en su propia labor intelectual, por incluir orgánicamente las corrientes religiosas de su tiempo y por atacar al cristianismo. Porfirio, después de seguir los cursos de Longino en Atenas, viajó a Roma, aproximadamente en el 263, para unirse a la escuela de Plotino; en el 269, por consejo de su maestro, viaja a Sicilia, prácticamente para evitar un suicidio por depresión. Regresó a Roma después de la muerte de Plotino.

$Y$ con esto ya estamos a mitad del asunto. Desde el siglo XVIII, se conoce como neoplatonismo a la corriente de pensamiento que inició Plotino, aunque según testimonio de San Agustín, esos filósofos sólo se llamaban a sí mismos "platónicos". El neoplatonismo comienza el día en que los platonistas se ponen a buscar, en el diálogo Parménides de Platón, el secreto de su filosofía. En ese diálogo se discuten varias hipótesis que se desprenden de aceptar o de rechazar la hipótesis de que el Uno es. Este diálogo, que había sido leído como un mero ejercicio dialéctico, empieza a entenderse a otro nivel. Cada una de las hipótesis, según ellos, no es una mera posibilidad lógica, sino un nivel de la realidad. A la primera hipótesis: sólo existe el Uno, se le reconoce un status superior a todo lo que existe; el Uno es fuente de todo lo que existe; es anterior y distinto a todo lo que existe, está más allá de todo. De esta primera realidad, del Uno, por superabundancia, por exceso de su realidad, se desborda, y de él se desprende una segunda realidad que es el Intelecto; en éste se encuentran todos los seres; de su mismo ser, por la actividad propia, se genera la tercera realidad que es el Alma. Así pues, el Uno, el Intelecto y el Alma son los principios de todo lo que existe verdaderamente; ellas conforman la verdadera realidad de la que el mundo que conocemos es un mero reflejo, cambiante, perecedero, corruptible, sobre todo por la participación de la materia. Todos los seres surgen del Uno y tienden hacia él; de alguna manera han salido del Uno y buscan 
regresar a él. Perdóneseme esta simplificación excesiva, de lo que visto de cerca tiene muchas más aristas que no pueden ser expuestas ni discutidas aquí, si consigo como me propongo ser breve. Estas reflexiones apuntan, sin lugar a duda, a toda una concepción del hombre y del mundo que evidentemente tienen consecuencias en lo filosófico, en lo cultural y hasta en lo político. Por ejemplo, aunque las cuestiones políticas del imperio están aparentemente al margen de la filosofía de la época, las meditaciones neoplatónicas sobre el Uno pueden verse como una justificación ideológica del imperialismo, de la misma manera en que la monadología de Leibniz fue una justificación del orden político del siglo XVII, o como la teoría de la relatividad y nuestra imagen del mundo atómico está acaso en la base del auge de la democracia en nuestros días.

Aunque la opinión general considera a Plotino como el iniciador del neoplatonismo, el autor de que vamos a ocuparnos es Jámblico, que vivió entre la segunda mitad del siglo III y el primer cuarto del siglo IV d. C., pues fue él quien determinó el rumbo que habría de seguir esa corriente filosófica. Nacido en Celesiria, una región próspera y conflictiva a la vez, Jámblico perteneció a la nobleza ilustrada, lo cual le permitió tener una esmerada educación en los centros culturales más importantes: Alejandría y Cesarea. Allí recibió la influencia del neopitagorismo y del platonismo medio. Después de abandonar a su maestro, el aristotélico Anatolio, Jámblico entró en contacto con Porfirio, el discípulo más sobresaliente de Plotino. Por su obra, por su pensamiento y por su actividad pedagógica, este sirio fue la figura más representativa e influyente de su tiempo; prueba de ello son los títulos que sus seguidores le concedieron: el emperador Juliano, Proclo, Simplicio, Siriano, Juan Filópono y muchos otros lo llamaron el divino Jámblico; también recibió los títulos de grande, genio, admirable, el hombre que es el mejor exégeta de los asuntos intelectuales y demás hechos divinos, el sirio inspirado, el muy sabio Fénix, el famoso héroe, el gran benefactor del imperio, ilustre curador de las almas, el guardián genuino de la virtud y el divinísimo. El emperador Juliano lo comparó con Platón mismo y con Pitágoras.

Paradójicamente, la fama con que lo rodearon sus seguidores contribuyó a que su pensamiento fuera tergiversado y a que fuera considerado como un simple mago, entregado a vanas supersticiones: no sería raro que la actual multitud de charlatanes espiritistas se consideraran sus genuinos herederos. La división del imperio y la adopción del cristianismo como la religión oficial contribuye- 
NOTAS

ron a que gran parte de las doctrinas de Jámblico quedaran ocultas o marginadas en la tradición cultural de Occidente. Por el contrario, cuando en el siglo VI se cerró la Academia por orden imperial, algunos de los neoplatonistas se fueron a Persia; por eso, el pensamiento de Jámblico tuvo influencia, sobre todo, en el misticismo islámico y en los círculos sufitas.

Jámblico vivió, en alguna medida como nosotros, un cambio de época, una sociedad globalizada, profundos conflictos de todo orden. Si Geffcken lo tenía como el Hegel del siglo IV, no está de más añadir que en este principio de siglo y de milenio necesitaríamos, nos urgiría un Jámblico.

Querría ahora hacer alguna relación con lo que acaso fue el fenómeno más significativo para Occidente en ese tiempo y de consecuencias para el nuestro: me refiero a la adopción del cristianismo como la religión oficial del imperio. Como es de suponerse, Jámblico debió, por su educación, al menos tener noticia de figuras tan importantes para el cristianismo como lo fueron Clemente de Alejandría y Orígenes. Porfirio, su maestro o colega, atacó a los cristianos. Asimismo debió de enterarse de las persecuciones de Maximo Daia y de Diocleciano, y él mismo ha sido considerado enemigo de los cristianos, quizá no tan beligerante al darse cuenta que la nueva religión ganaba el ánimo del emperador.

El cristianismo, al menos al principio y en principio, estuvo alejado de la política. Sus creyentes no tenían obligación ninguna de buscar la transformación del orden social; por el contrario, debían estar sometidos a él voluntariamente (Rm, 13, 1-7; Mt, 22, 16-21; Flm); Así se lee en la Carta a Diogneto, escrito del siglo II:

Los cristianos no se distinguen de los demás hombres, ni por el lugar en el que viven, ni por su lenguaje, ni por sus costumbres. Ellos, en efecto, no tienen ciudades propias, ni utilizan hablar insólito, ni llevan un género de vida distinto. Su sistema doctrinal no ha sido inventado gracias al talento y especulación de hombres estudiosos, ni profesan, como otros, una enseñanza basada en autoridad de hombres.

Viven en ciudades griegas y bárbaras, según les cupo en suerte, siguen las costumbres de los habitantes del país, tanto en el vestir como en todo su estilo de vida y, sin embargo, dan muestras de un tenor de vida admirable y, a juicio de todos, increíble. Habitan en su propia patria, pero como forasteros; toman parte en todo como ciudadanos, pero lo soportan todo como extranjeros; toda tierra extraña es patria para ellos, pero están en toda patria como en tierra extraña. 
Igual que todos se casan y engendran hijos, pero no se deshacen de los hijos que conciben. Tienen la mesa en común, pero no la cama.

Viven en la carne, pero no según la carne. Viven en la tierra, pero su ciudadanía está en el cielo. Obedecen las leyes establecidas, y con su modo de vivir superan estas leyes. Aman a todos, y todos los persiguen. Se los condena sin conocerlos. Se les da muerte, y con ello reciben la vida. Son pobres, y enriquecen a muchos; carecen de todo, y abundan en todo. Sufren la deshonra, y ello les sirve de gloria; sufren detrimento en su fama, y ello atestigua su justicia. Son maldecidos, y bendicen; son tratados con ignominia, y ellos, a cambio, devuelven honor. Hacen el bien, y son castigados como malhechores; y a ser castigados a muerte, se alegran como si se les diera la vida. Los judíos los combaten como a extraños y los gentiles los persiguen, $y, \sin$ embargo, los mismos que los aborrecen no saben explicar el motivo de su enemistad. ${ }^{1}$

Quise ser extenso deliberadamente para dejar ver cómo el cristianismo sonaba entonces como una novedad absoluta. Si se toma en serio a Diogneto, el cristianismo no debía afectar mayormente la vida a su alrededor, toda vez que su régimen de vida, como escuchamos, no era distin-

1 "Carta a Diogneto", en Liturgia de las Horas, 1982, México, ed. Él, t. II, pp. 846-7. to del todo al de sus vecinos. Sin embargo, el imperio se vio obligado a tomar una actitud antagónica frente al cristianismo, pues, como veremos, una convicción religiosa afecta la vida de una comunidad hasta en detalles que a veces perdemos de vista. Plinio, al escribir al emperador Trajano, pidiendo consejo sobre qué debía hacerse con los cristianos, escribe:

Decían los cristianos que todo su error o falta se limitaba a estos puntos: que en determinado día se reunían antes de salir el sol y cantaban sucesivamente himnos en honor de Cristo, como si fuese Dios; que se obligaban bajo juramento, no para crímenes, sino a no cometer robo ni adulterio; a no faltar a la promesa, a no negar el depósito: que después de esto, acostumbraban separarse, y que después se reunían en común para comer manjares inocentes; que habían dejado de hacerlo después de mi edicto, por el cual, según tus órdenes, prohibí toda clase de reuniones. Esto me ha hecho considerar tanto más necesario arrancar la verdad por la fuerza de tormentos a dos esclavas, cuanto que decían estaban enteradas de los misterios del culto; pero solamente he encontrado una deplorable superstición llevada hasta el exceso; y por esta razón lo he suspendido todo para pedirte órdenes. El asunto me parece digno de tus reflexiones, por la multitud de los que se han puesto en peligro; porque diaria- 
NOTAS

mente se verán envueltas en estas acusaciones multitud de personas de toda edad, clase y sexo. Este mal contagioso no solamente ha infestado las ciudades, sino que también las aldeas y los campos. Creo, sin embargo, que puede ponerse remedio y detenerlo. Lo cierto es que los templos, que estaban desiertos, son frecuentados y que comienzan de nuevo los sacrificios que se olvidaban. Por todas partes se venden víctimas, que antes tenían pocos compradores; comprendiéndose por esto a cuántos se les puede separar de su extravío si se perdona a los arrepentidos. $^{2}$

Quiero llamar su atención al detalle de que la economía, al menos de quienes vendían las víctimas, estaba seriamente afectada por la praxis cristiana. En cuanto a lo demás, se nota la consonancia de Plinio con Tácito, que acusara a los cristianos de odio al género humano. Además del régimen comunitario de vida, las actividades proselitistas y la transformaciones de las costumbres sociales, el monoteísmo excluyente fue una razón del enfrentamiento entre el cristianismo y el imperio. El motivo del antagonismo fue que el imperio se había perfilado, sobre todo a partir de Heliogábalo (218-222), como una teocracia. Pero en el siglo III, la Iglesia no sólo

${ }^{2}$ Plinio el Joven, "Carta XCVII", en Cartas, 1984, México, SEP, col. Cien del mundo, selección y notas de Roberto Heredia, pp. 350-1. era una organización más sólida, sino que contaba ya entre sus miembros con personas acomodadas e influyentes, y consiguientemente le fue más difícil mantenerse al margen de la política. Contemporáneo de Jámblico, Eusebio de Cesarea buscó y logró poner a Constantino del lado de los cristianos, al considerarlo la realización temporal de la escatología.

Por el contrario, para los platonistas la política era un asunto de primer orden. El orden político debía de seguir el patrón del orden metafísico. En el terreno práctico deben recordarse las tentativas sin éxito de plotino por fundar Platonópolis. En lo que respecta a Jámblico, el hombre debe considerarse el ciudadano de una ciudad divinizada, a fin de conseguir asimilarse a dios, de acuerdo con la divisa del diálogo platónico Teeteto. Como miembro de la aristocracia noble y terrateniente de entonces, Jámblico debió de hacer de sus territorios el lugar de sus prácticas políticas. Al menos se sabe que propugnó por llevar a la práctica el ideal de las comunidades pitagóricas, que en más de un aspecto se parecía al de las comunidades cristianas, en la vida en común, la comunión de bienes, ciertas prácticas ascéticas y de disciplina. En el terreno de los hechos, al buscar que el orden político fuera una imagen del orden trascendental, en el caso de los platónicos, o imagen anticipada del mundo futuro en el 
caso de los cristianos, las diferencias ya no son tan notorias y se acentúan las coincidencias. La Iglesia, como aquellos filósofos platónicos, pretendió regular el orden terrenal y no sólo a los adeptos cristianos, y es difícil no ver en la política eclesiástica de la Edad media resabios de las intenciones platónicas. Es pertinente señalar una diferencia entre Porfirio y Jámblico: aquél tendía a confundir la esencia de los órdenes superiores y no considerar distintos entre sí al Uno, al Intelecto y al Alma; en cambio, Jámblico hacía una clara distinción entre ellos y, además, acentuaba su distribución jerárquica, y si el orden social debe ser reflejo del orden trascendente, es posible que un pensamiento como el de Jámblico contribuyera a fijar las clases sociales durante la Edad Media, separándolas netamente unas de otras y jerarquizándolas entre sí.

Considerando la situación del imperio romano durante el siglo III, no es raro que la economía se haya vuelto un tema de peculiar importancia, aun entre comunidades que, como la cristiana o la neoplatónica, decían no interesarse en este mundo de lo no verdadero para unos y valle de lágrimas para los otros. En el caso del cristianismo, no son pocas las exhortaciones de los predicadores a la limosna; no pienso insistir en ello, dado que era muy claro desde el fundador que no podía servirse a Dios y al dinero. En cuanto a Jámblico, es difícil saber a ciencia cierta su postura. Él mismo, por su estirpe, descendiente de los antiguos reyes de Emesa, de familia opulenta y próspera, no debió ser ajeno a tales problemas particularmente acentuados en sus rumbos. Como filósofo, no parece haber renunciado a las comodidades de su clase. Se tiene noticia de que tenía varias villas de descanso y de que asistía a los refinados baños de Gadara. Es significativa la siguiente anécdota: mientras daba clase, Alipio, uno de los que escuchaba, le pregunta irónico: “dime, filósofo, ¿el rico es justo o injusto? Porque no hay término medio", a lo que él, antes de retirarse, replicó que sus lecciones no versaban sobre la riqueza, sino sobre la virtud. Juliano, el emperador, escribía así a Prisco: "te suplico que no te aturdan los oídos los seguidores de Teodoro, quienes dicen que Jámblico, el verdaderamente divino y el tercero después de Pitágoras y de Platón, fue un ambicioso". Al margen de estas anécdotas, el capítulo veinte de su Protréptico a la filosofía es muestra de la preocupación por la economía; allí, "después de haber exaltado los beneficios del orden público, propios para crear un clima de confianza, denuncia el marasmo provocado por el atesoramiento individual, los capitales congelados o fuera de circulación. Haría falta esperar a un Adam Smith para encontrar 
NOTAS

una rigurosa denuncia de los daños causados por la capitalización improductiva". ${ }^{3}$ El texto es el siguiente, y los invito a leerlo como si se tratara de la situación actual:

Los males que resultan de la falta de leyes son los siguientes: antes que nada, los hombres se quedan sin tiempo libre para las obras, y se preocupan de lo más desagradable, de los negocios, pero no de las obras que les son propias; $\mathrm{y}$ atesoran riqueza a causa de la desconfianza y de la falta de relaciones comerciales, pero no la ponen en común y, así, se hace insuficiente, aunque haya mucha.

Las fortunas inútiles y las buenas sirven para cosas contrarias, pues la buena fortuna no es segura en la falta de leyes, sino que es objeto de insidias; y la mala fortuna no se aparta, sino que se afianza a causa de la desconfianza y de la falta de relaciones comerciales. La guerra exterior y la civil ocasiona más sedición, por la misma causa; si no se produce antes, sucede entonces. Ocurre que siempre se detienen los negocios, por los ataques entre unos y otros, por los cuales pasan la vida poniéndose en guardia y atacándose a su vez entre sí.

Y ni los que están despiertos tienen pensamientos agradables, ni

${ }^{3}$ Jean-Paul Dumont, "Jamblique, lecteur des sophistes. Problème du Protreptique", Le néoplatonisme (Actes du Colloque de Royaumont, 9-13 Juin, 1969, Colloques Internationaux du Centre National de la Recherche Scientifique), 1971, Paris, Éd. du CNRS, p. 208. los que se entregan al sueño lo tienen agradable, sino acompañado de miedo, y su despertar es temeroso y asusta al hombre por traer recuerdos repentinos de los males; éstos y también todos los otros males antedichos resultan por la falta de leyes.

Se origina también la tiranía, mal tan grande y tan nocivo, no por otra causa que por la falta de leyes. Algunos de los hombres que no piensan correctamente creen que el tirano se establece por alguna otra causa, y conjeturan, porque no razonan correctamente estas cosas, que los hombres son despojados de su libertad, sin ser ellos los culpables, sino que son obligados por el tirano que se ha establecido. En efecto, cualquiera que cree que un rey o un tirano surge por alguna otra razón que la falta de leyes y de la ambición, es un insensato. Pues cuando todos se inclinan a la maldad, entonces surge la tiranía. Pues no es posible que los hombres vivan $\sin$ leyes y sin justicia. Cuando estas dos, la ley y la justicia, se apartan de la multitud, entonces la protección y la vigilancia de ellas se va hacia uno solo. ¿Cómo, pues, de otra manera recaería la monarquía en uno solo, a menos que la ley haya sido desplazada de lo que conviene a la multitud? Pues es necesario que este hombre, que abolirá y suprimirá la ley común y que conviene a todos, se vuelva de acero, si va a arrebatar estas cosas de la multitud de los hombres, siendo uno, de entre muchos. Siendo carnal y semejante a la mayoría, no podría hacer estas cosas; 
mas estableciendo lo contrario que estaba abandonado, podría ser el monarca. Por esto también lo que ocurre se le oculta a algunos de los hombres. ${ }^{4}$

Finalmente, como la prudencia manda seguir el dicho que dice "sé breve y agradarás", sólo quiero mencionar otros caminos posibles de seguir estudiando a Jámblico, al cristianismo antiguo, a la Antigüedad tardía, que de momento no me ha sido posible tratar extensamente. El más importante acaso sea el tema de la relación que guardan fe y razón. Las posturas dentro del cristianismo van desde la cerrazón total de Tertuliano, para quien no había diálogo posible, pero ni siquiera le parecía necesario, entre Atenas y Jerusalén. O la posición de Clemente de Alejandría, para quien una fe que no soportara el análisis de la razón, bien podría perderse. En todo caso habría que usar la filosofía no cristiana, tomando ejemplo de ese antiguo cristianismo, que pensaba que, así como los israelitas salieron de Egipto despojándolos de sus tesoros, no habría que renunciar a los logros del pensamiento donde quiera que se encuentre. Ya para Justino, por ejemplo, donde quiera que hubiera estado el logos, allí estaba Cristo, y por eso habrían sido cristianos Sócrates, Heráclito, Platón, etcétera; estos filósofos, además, en la mente del Clemente de Alejandría, eran como una especie de Antiguo Testamento de los paganos. Jámblico por su parte, escribió una obra conocida como Acerca de los misterios de Egipto, título abreviado del que le diera Marsilio Ficino al hacer la traducción latina. En ella, Jámblico defiende la teúrgia, es decir, las obras de los dioses en los ritos. La religión para él tiene un lugar superior a la razón, pero que no se puede alcanzar sin la razón. Ésta, por su parte, sólo se desarrolla con la virtud. Argumenta en su obra la validez del culto y de la plegaria, argumentos que después usará la Iglesia católica para justificar la validez de los sacramentos. Se trata nada más, pero nada menos, quizá del primer tratado de filosofía de la religión. El mérito de ambos, del cristianismo y de Jámblico, radica en haber elaborado una síntesis entre religión, filosofía y praxis ética. Y en ese sentido habría que buscar inspiración para nuestro tiempo.

${ }^{4}$ Jamblique, Protreptique, 1989, Paris, "Les Belles Lettres", ed. Édouard Des Places, S.J.; la traducción es mía. 
CITAM Derechos Reservados.

La reproducción total o parcial de este artículo se podrá hacer si el ITAM otorga la autorización previamente por escrito. 